\title{
Near-well simulation of oil production from a horizontal well with ICD and AICD completions in the Johan Sverdrup field using OLGA/ROCX
}

\author{
Ali Moradi, Britt Margrethe Emilie Moldestad \\ Department of Process, Energy and Environmental Technology, University of South-Eastern Norway, Norway. \\ \{ali.moradi@usn.no, britt.moldestad@usn.no\}
}

\begin{abstract}
One of the main principles of improving oil recovery is maximizing the contact area between the well and the reservoir. To achieve this purpose especially in reservoirs with a thin oil column, long horizontal wells are widely used today. However, there are some challenges related to horizontal wells like water coning towards the heel due to the heel-toe effect as well as early water breakthrough owing to heterogeneity along the well. In order to tackle these issues, passive inflow control devices (ICDs) and autonomous inflow control devices (AICDs) can be used. ICDs are able to balance the drawdown pressure along the horizontal well and as a result, postpone the early water breakthrough. By applying AICDs, in addition to postponing the early water breakthrough, water can be partially choked back autonomously, and the negative impacts of early water breakthrough will be attenuated. The Johan Sverdrup field (JSF) is a giant oil field located in the North Sea and production from this field has been started recently. Since there is a plan for developing this oil field in the near future, and a few studies have been done on this field so far, further studies are needed to obtain more cost-effective oil recovery in this field. The main objective of this paper is near-well simulation of oil production from the well 16/2-D-12 in the JSF by considering ICD and AICD completions. The simulation has been conducted based on the characteristics of the reservoir near this well for 750 days of oil production. OLGA in combination with ROCX has been used as a simulation tool. The simulation results showed that by applying both ICDs and AICDs the heel-toe effect, and heterogeneity along the well can be effectively handled and the water breakthrough time can be delayed by 255 days. Moreover, it was observed that by completion of the well 16/2-D-12 with AICDs, the accumulated water production can be reduced by $11.9 \%$ compared to using ICDs. In the same way, by using AICDs the flow rate of water production is reduced by $13.4 \%$ after 750 days. Furthermore, the results showed that using AICDs has a negligible impact on both the accumulated and the flow rate of oil production compared to using ICDs. Therefore, by completion of the well 16/2-D-12 with AICDs more cost-effective oil production can be achieved.
\end{abstract}

Keywords: horizontal well, ICD, AICD, OLGA, ROCX

\section{Introduction}

Despite the rapid progress in the area of renewable energy, fossil fuels will remain the world's most important energy source for the years to come. Therefore, in order to meet future energy demands, increasing oil production and reducing carbon footprint from the oil and gas sector must be in the spotlight. Increasing oil production requires massive investments to explore and develop new oil fields. For stimulating new investments in the oil industry, new technologies and methods must be applied for increasing the efficiency of oil production and achieving maximum profit per barrel of oil. Oil production from the Johan Sverdrup field has been started recently. With the aim of obtaining maximum oil recovery, cutting-edge technologies have been applied in this field and further studies are needed to improve these technologies. The well 16/2-D-12 is a horizontal well located in the JSF and compared to other wells in this field, there is more information available related to the characteristics of the reservoir near this well. Therefore, this paper focuses on making a model for near-well simulation of oil production from the well 16/2-D-12. By using this simulation model, the functionality of ICDs and AICDs in improving oil recovery from the JSF is investigated.

Preparing a realistic model for the simulation of oil production needs to know the realistic characteristics of the reservoir. Since the extraction of oil from the JSF has just started, there is limited information available in the literature describing the characteristics of this field. As a result, determining some characteristics of the field like the viscosity of oil in the reservoir, anisotropy of permeability, wettability and relative permeability, etc. is not straightforward and needs curve-fitting on existing data, calculation by using general equations or some close to the mark assumptions. Moreover, due to the lack of information about the heterogeneity of the reservoir along the well with respect to permeability, the model is prepared for a heterogeneous reservoir with some random high permeable zones in different directions. In the following subchapters, the main steps for developing the simulation model as well as the simulation results are described and discussed. 


\section{Inflow control technologies}

The horizontal well technology is wildly used for increasing the efficiency of oil recovery. One of the major problems that can reduce the efficiency of using horizontal wells is early gas and water coning. This problem gives rise to an uneven inflow profile along the horizontal well. Inflow control technologies are used to counteract the non-uniform inflow throughout the length of the horizontal well leading to improve the well performance and efficiency.

\subsection{Passive Inflow Control Devices}

One of the mature technologies that have been developed for managing the early water breakthrough in horizontal wells is passive Inflow Control Devices (ICDs). A passive ICD is a flow restrictor device with no moving part installed as a part of the sandface completion hardware. ICDs are used for chocking the flow by adding extra pressure drop and thereby even out the flow influx along a horizontal well. As Figure 1 is showing, ICDs can delay the early water breakthrough by balancing the inflow along the well and as a result, increasing the oil production (Aakre, 2017).

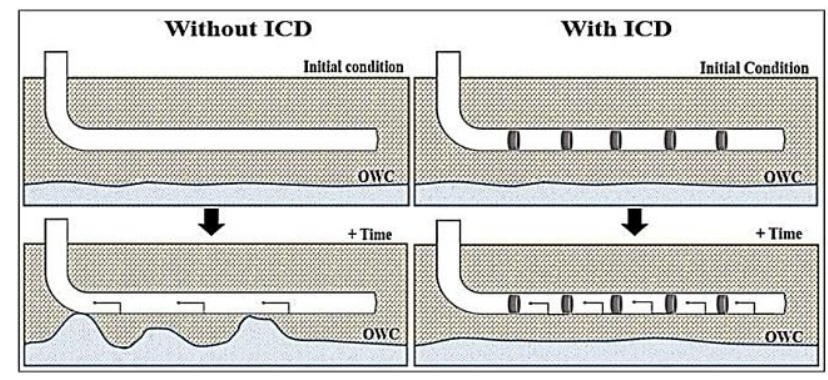

Figure 1. Application of ICDs in mitigation of the early water breakthrough (Chammout et al, 2017).

One of the main drawbacks of passive ICDs is that they are not able to choke the water back after breakthrough. In this condition, the well must be shut in to avoid increasing the water cut more than the capacity of the separation facilities and it leads to the reduction of oil production (Aakre, 2017).

Horizontal wells are completed with many ICDs distributed along the well. The pressure drop across an ICD is a function of flow rate, the geometry of ICD, and the fluid density but it does not depend on the fluid viscosity. The mathematical equation governing the behavior of orifice-type ICDs is:

$$
\dot{Q}=C_{D} A \sqrt{\frac{1}{1-\beta^{4}}} \cdot \sqrt{\frac{2 \Delta P}{\rho}}
$$

where $\dot{Q}$ is the volume flow rate of the fluid passing through the ICD, $\Delta P$ is the pressure drop over the ICD, $\rho$ is the fluid density and $\beta=d / D$ ( $d$ and $D$ are the diameters of the orifice and production tubing respectively). In Equation 1, $C_{D}$ is called discharge coefficient. It can be calculated as $C_{D}=A / A_{v c}$ in which $A$ is the cross-sectional area of the orifice hole and $A_{v c}$ is the minimum jet area just downstream of the orifice called Vena Contracta (The Engineering ToolBox, 2004).

\subsection{Autonomus Inflow Control Devices}

Since passive ICDs have no ability to choke the water or gas back after breakthrough, Autonomous Inflow Control Devices (AICDs) have been developed as a robust alternative in recent years. AICDs have a moveable disk and they can be partially closed for low viscous fluids compared to oil like water and gas. As a result, in addition to delaying the water or gas breakthrough, AICDs can reduce the production of water or gas after breakthrough autonomously and increase oil production compared to passive ICDs with no need to control from the surface (Aakre, 2017).

AICDs are available with different designs and one of the most widely used types of AICDs has been developed by Norsk Hydro and Statoil and is called Rate Control Production (RCP). As Figure 2 shows, this type of AICD consists of three parts, which are the valve body, the nozzle, and the free-floating disk. The valve is designed based on the fluid properties in such a way that when oil passes through the valve, the pressure at the inlet is higher and the disk rests at the seat. Thus, the maximum flow area is obtained and as a result, the maximum amount of oil passes through the valve. Besides, the position of the moveable disk can vary based on the fluid properties and flow conditions. Owing to the special design of this valve, when low viscous fluids like water or gas enter the valve, the pressure at the inlet becomes lower. Consequently, based on Bernoulli's equation the total force acting on the disk pulls it towards the inlet, and the flow area is partially closed. Therefore, RCPs can minimize the flow rate of unwanted fluids like water or gas autonomously (Mathiesen et al, 2011; Askvik and Sørheim, 2017).

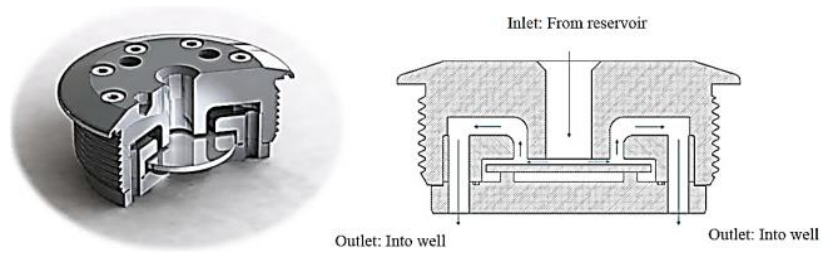

Figure 2. Statoil's RCP valve and its schematic sketch (Mathiesen et al, 2011).

The pressure drop across an RCP valve can be determined by an empirical mathematical function developed and validated by Statoil, and it is represented as:

$$
\Delta P=f(\rho, \mu) \cdot a_{\text {AICD }} \cdot \dot{Q}^{x}
$$

where $\dot{Q}$ is the volumetric flow rate of fluid, and $a_{A I C D}$ and $x$ are user-input parameters depending on the RCP 
design and fluid properties. $f(\rho, \mu)$ is an analytical function of fluid density and viscosity and defined as:

$$
f(\rho, \mu)=\left(\frac{\rho_{\text {mix }}^{2}}{\rho_{\text {cal }}}\right) \cdot\left(\frac{\mu_{c a l}}{\mu_{\text {mix }}}\right)^{y}
$$

where $y$ is a user-input parameter, and $\rho_{\text {cal }}$ and $\mu_{\text {cal }}$ are specified as calibration density and viscosity respectively. Moreover, $\rho_{m i x}$ and $\mu_{m i x}$ are the density and viscosity of the mixture of fluids passing through the RCP valve and are defined by:

$$
\begin{aligned}
& \rho_{\text {mix }}=\alpha_{\text {oil }} \rho_{\text {oil }}+\alpha_{\text {water }} \rho_{\text {water }}+\alpha_{\text {gas }} \rho_{\text {gas }} \\
& \mu_{\text {mix }}=\alpha_{\text {oil }} \mu_{\text {oil }}+\alpha_{\text {water }} \mu_{\text {water }}+\alpha_{\text {gas }} \mu_{\text {gas }}
\end{aligned}
$$

where $\alpha_{\text {oil }}, \alpha_{\text {water }}$ and $\alpha_{\text {gas }}$ are the volume fraction of oil, water and gas in the mixture respectively (Halvorsen et al, 2016).

\section{Characteristics of the reservoir near the well 16/2-D-12}

To prepare a realistic model for simulation of oil production from the well 16/2-D-12 in OLGA/ROCX it is necessary to know the realistic characteristics of the reservoir near the drainage area of this well. Based on the well test data, the temperature of the reservoir near the well $16 / 2-\mathrm{D}-12$ is $81^{\circ} \mathrm{C}(354 \mathrm{~K})$. Moreover, by using the reported formation pressure data, the formation pressure near this well can be approximated to be about 240 bar.

There is no information about the viscosity of crude oil at the reservoir conditions near the well 16/2-D-12. However, its value is known in temperatures $293 \mathrm{~K}, 313$ $\mathrm{K}$, and $323 \mathrm{~K}$ and they are given in the Equinor's crude summary report (Equinor, 2020). Based on the available values, the value of crude oil viscosity at the reservoir conditions (the pressure of 240 bar and the temperature of $354 \mathrm{~K}$ ) can be extrapolated. The method used for extrapolation is based on the linear regression and a commonly used mathematical model between temperature and viscosity described by Equation 5 . Figure 3 illustrates the fitted curve and the viscosity of oil at the reservoir temperature calculated by MATLAB.

$$
\mu=A e^{B / T}
$$

By using curve-fitting on the known values of viscosity and the well test data provided by NPD, the given information in Table 1 for crude oil properties has been collected (Norwegian Petroleum Directorate, 2020).

Table 1. Crude oil properties near the well 16/2-D-12.

\begin{tabular}{|c|c|}
\hline Parameter & Value \\
\hline API gravity & 28.0 \\
\hline Viscosity & $3 \mathrm{cP}$ \\
\hline GOR & $44 \mathrm{Sm}^{3} / \mathrm{Sm}^{3}$ \\
\hline
\end{tabular}

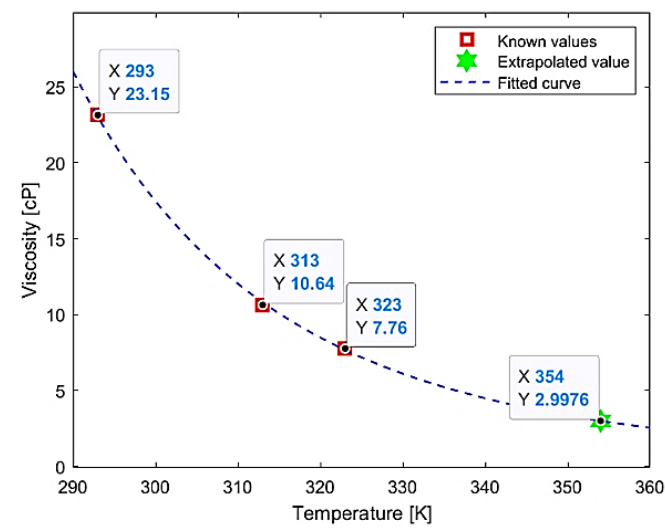

Figure 3. Estimation of crude oil viscosity at the reservoir temperature by curve-fitting on the known values.

According to the NPD's well test data obtained from the reservoir near the well 16/2-D-12 (Norwegian Petroleum Directorate, 2020), the main reservoir has an oil column of $67.5 \mathrm{~m}$ started from the depth of $1877 \mathrm{~m}$ and ended to the depth of $1944.5 \mathrm{~m}$. Moreover, the reservoir is located in two zones with different types of sandstone. From the depth of $1877 \mathrm{~m}$ to $1911 \mathrm{~m}$, the reservoir is located in the Intra Draupne sandstone formation, and between the depth of $1911 \mathrm{~m}$ and 1944.5 $\mathrm{m}$, it is mostly located in the Vestland Group sandstones. Based on the obtained information from the analysis of the well $\log$ data near the well 16/2-D-12, the thickness of the net pay zone, the shale volume, and water saturation of the reservoir near this well have been calculated and summarized in Table 2 (Kaspersen, 2016).

Table 2. Thickness of the net pay zone, average water saturation, and shale volume near the well 16/2-D-12.

\begin{tabular}{|c|c|c|c|}
\hline Zone & $\begin{array}{c}\text { Net Pay } \\
\text { Thick. }\end{array}$ & Average $\mathbf{S}_{\mathbf{w}}$ & Average $\mathbf{V}_{\text {sh }}$ \\
\hline Zone 1 & $32.46 \mathrm{~m}$ & 0.062 & 0.09 \\
\hline Zone 2 & $22.86 \mathrm{~m}$ & 0.322 & 0.122 \\
\hline
\end{tabular}

Based on the analysis of well logs, the average effective porosity for both zones of the reservoir near the well $16 / 2$-D-12 is 0.27 . The median permeability near this well is $14.7 \mathrm{D}$ but it varies between 0.5 and $40 \mathrm{D}$ throughout the JSF. (Kaspersen, 2016).

By using the given data in Table 2, and Equations 6,7 and 8 which are empirical correlations for the sandstone reservoir, the anisotropy permeability, $a=k_{v} / k_{H}$, near the well 16/2-D-12 can be calculated (Iheanacho et el, 2012).

$$
\begin{gathered}
k_{H}=\sqrt{k_{x} k_{y}} \\
k=\sqrt[3]{k_{x} k_{y} k_{z}} \\
k_{v}=k_{z}=0.0718 \times \sqrt{\left[\frac{k_{H}\left(1-V_{s h}\right)}{\phi_{e}}\right]^{2.0901}}
\end{gathered}
$$


The results of the permeability anisotropy calculation are given in Table 3 .

Table 3. Permeability anisotropy near the well 16/2-D-12.

\begin{tabular}{|c|c|c|c|c|}
\hline Parameter & $k_{x}$ & $k_{y}$ & $k_{z}$ & $a$ \\
\hline Value & $22.2 \mathrm{D}$ & $22.2 \mathrm{D}$ & $6.4 \mathrm{D}$ & 0.3 \\
\hline
\end{tabular}

The wettability in a reservoir depends on several factors like polar components in oil, formation water composition, and salinity as well as rock composition. By considering all these parameters and criteria it can be believed that the Johan Sverdrup reservoir has a mixedwet wettability state (Fang, 2017).

Since there is no information about the relative permeability of the Johan Sverdrup reservoir, this parameter must be estimated based on the available information about the relative permeability of the other sandstone reservoirs in the North Sea with almost the same characteristics. The Frøy field is located in the central part of the North Sea. Frøy is a sandstone reservoir with high porosity and absolute permeability almost like the Johan Sverdrup reservoir. It also has some mixed-wet zones like the Johan Sverdrup reservoir. As a result, the values of relative permeability of the Johan Sverdrup reservoir can be considered almost the same as that of the Frøy reservoir in the mixed-wet zones (Tangen, 2012; Hadia et al, 2011). Figure 4 shows the relative permeability curves based on the relative permeability in the mixed-wet zones of the Frøy field and they can be used for the Johan Sverdrup reservoir as well.

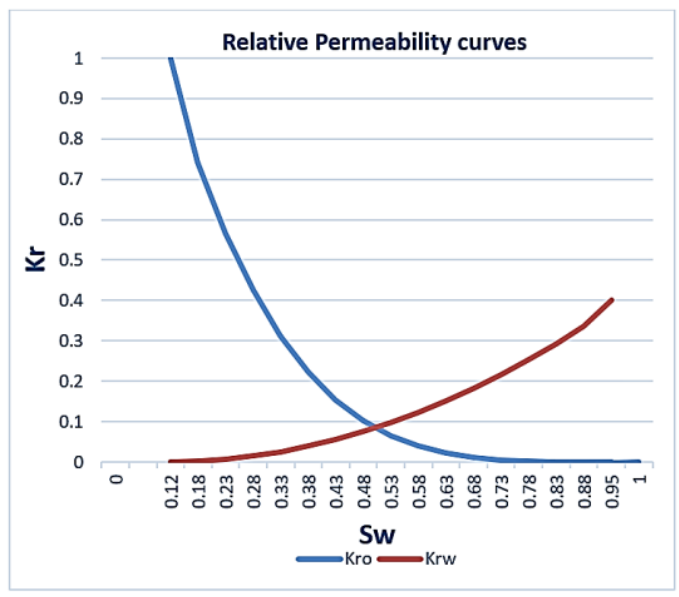

Figure 4. Relative permeability curves for the Johan Sverdrup reservoir.

\section{Development of the OLGA/ROCX model}

The combination of OLGA and ROCX creates one of the leading and robust tools for modeling and simulation of multiphase flow behavior from the reservoir pore to the production pipe and process facilities. OLGA is a dynamic multiphase flow simulator and ROCX is a reservoir simulator that can be coupled to OLGA as a plug-in.

\subsection{Development of the reservoir model in ROCX}

In this subchapter, the main settings for developing the model of the reservoir near the well 16/2-D-12 in ROCX are described.

\subsubsection{Determining the dimensions of the reservoir drainage area and the grid setting}

In order to create a near-wellbore model of oil production, the first step is to determine the dimensions of the drainage area near the well. The drainage area of a horizontal well has an ellipsoidal shape. However, due to the ROCX limitation for creating an ellipsoidal geometry, a rectangular drainage area is considered for developing the model. As mentioned in Table 2 the total thickness of the net pay reservoir near the well 16/2-D12 is $55.5 \mathrm{~m}(32.46+22.86=55.32 \sim 55.5 \mathrm{~m})$. Therefore, the height of the drainage area is considered to be equal to $55.5 \mathrm{~m}$.

There is no information about the exact geometry of the well 16/2-D-12 in the literature. Therefore, based on the classification of horizontal wells it is assumed that the well $16 / 2-\mathrm{D}-12$ is a medium radius horizontal well with the maximum radius in the kickoff section which means $R_{\text {kickoff }}=305 \mathrm{~m}$. According to the NPD's fact pages (Norwegian Petroleum Directorate, 2020), the measured depth of the well $16 / 2-\mathrm{D}-12$ is $L_{M D}=3875 \mathrm{~m}$ and it has the final vertical depth of $L_{T V D}=1876 \mathrm{~m}$. As a result, the length of the horizontal section of this well, Lhorizontal, can be calculated by Equation 9 .

$$
L_{M D}=L_{T V D}+L_{\text {kickoff }}+L_{\text {horizontal }}
$$

By using Equation 9 the length of the horizontal section of the well is calculated as $1612 \mathrm{~m}$. Therefore, the length of the drainage area is considered the same as that of the horizontal section of the well. To determine the width of the drainage area, oil production from five test cases with similar heigh and length but different width of the drainage area is simulated in OLGA. The simulations are conducted for a horizontal well with a length of 124 $\mathrm{m}$ and one ICD valve in a reservoir with the same rock and fluid properties as the JSF. Figure 5 shows the accumulated oil production during 120 days of simulation for the given cases. As can be seen in the figure, by increasing the width of the drainage area, the time of water breakthrough and accumulated oil production increases, but it has a converging pattern in such a way that there is no big difference between accumulated oil production in the cases with a width of $120 \mathrm{~m}$ and $140 \mathrm{~m}$. As a result, it can be concluded that 
considering the width of the drainage area for the main model equal to $120 \mathrm{~m}$ can be a good estimation. Of course, considering the width of the drainage area equal to $140 \mathrm{~m}$ leads to more accurate results, however, it also increases the time of the simulation.

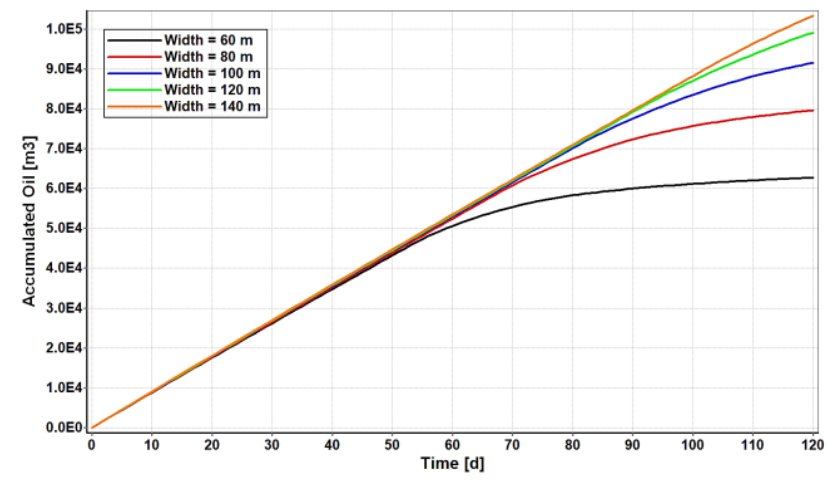

Figure 5. Analysis of the sensitivity of oil production to the width of the drainage area.

Since in the JSF oil is produced by water drive, the well must be positioned as near as possible to the top of the drainage area to delay water breakthrough. Therefore, for developing the model, it is assumed that the well is located $5.5 \mathrm{~m}$ below the top of the drainage area. The geometry of the drainage area and the position of the well, considered for developing the model of oil production from the well $16 / 2-\mathrm{D}-12$ in the JSF is schematically depicted in Figure 6.

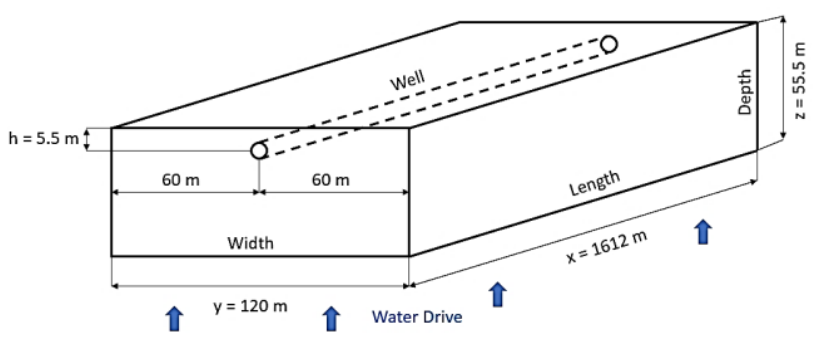

Figure 6: Schematic geometry of the drainage area.

To discretize the reservoir in ROCX, the number of grids in $(x, y, z)$ coordinates must be determined. In general, a suitable grid setting can be achieved by using finer mesh in the places with high variation in the fluid properties and coarser mesh in the other places. Since the cross-section of the reservoir is located in the $Y-Z$ plane, the fluid pressure in the $\mathrm{Y}-\mathrm{Z}$ plane around the well drops significantly. Therefore, to achieve more accurate results, finer mesh in the $y$ and $z$ directions close to the well must be defined in the grid setup. The length of the well is in the $x$-direction. As a result, the fluid pressure has small variations in the $x$-direction, and considering uniform mesh in the $x$-direction can maintain enough accuracy. In order to develop the model, it is assumed that the well 16/2-D-12 contains 13 joints, each $124 \mathrm{~m}$ long and consisting of one equivalent valve. As a result, 13 uniform cells are considered for the reservoir in the $x$-direction. In the $y$ and $z$ directions, the meshes are not uniform, and the grid resolution in these directions is shown in Figure 7.

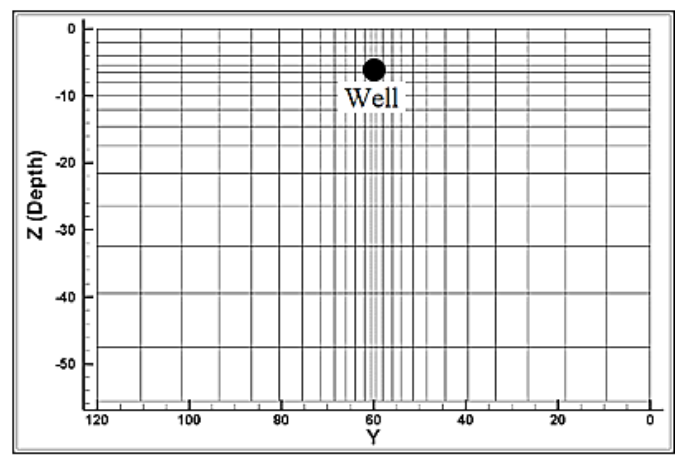

Figure 7. Grid resolution in the $\mathrm{Y}-\mathrm{Z}$ plane.

\subsubsection{Reservoir property settings}

Since the Johan Sverdrup reservoir is heterogeneous with respect to permeability, for the investigation of the oil production from the well 16/2-D-12, the OLGA/ROCX model is developed for a heterogeneous reservoir. The permeability in the JSF varies between 0.5 and $40 \mathrm{D}$ while the average permeability in the reservoir near the well 16/2-D-12 is $14.7 \mathrm{D}$. As a result, there are some places in the reservoir where the permeability is more than the average permeability. Moreover, heterogeneity may exist in the horizontal, vertical, or angled direction. Therefore, for creating a heterogeneous case, the permeability in some random zones in the horizontal, vertical, and angled directions is considered 1.5, 2, and 2.5 times higher than the average permeability in the near-well reservoir. MATLAB is used for generating required data for the implementation of heterogeneity in ROCX. By considering the permeability anisotropy given in Table 3 , the average permeability in the $x$ and $y$ directions is equal to $22.2 \mathrm{D}$, and average permeability in the $z$-direction is equal to $6.4 \mathrm{D}$ throughout the reservoir. The permeability distribution in the heterogeneous reservoir in the $z-$ direction used for developing the OLGA/ROCX model is shown in Figure 8. The permeability distribution in the $x$ and $y$ directions has the same pattern.

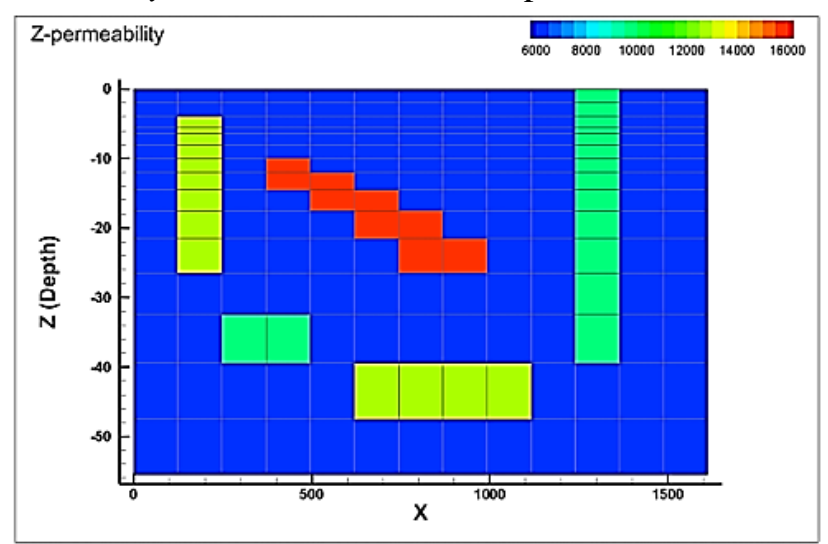

Figure 8. Permeability distribution in the reservoir. 


\subsubsection{Initial condition settings}

Based on the information given in Table 2, the reservoir near the well 16/2-D-12 consists of two zones with different types of sandstone. Therefore, for developing the model it is assumed that initially the reservoir is filled with oil in both zones, but with a water saturation of 0.062 and 0.322 in the first and second zone respectively. Figure 9 represents the initial water saturation in the reservoir.

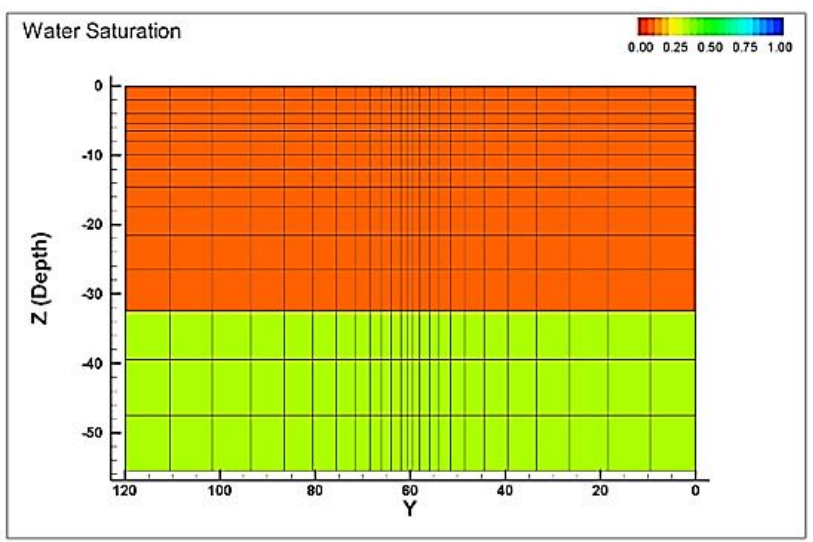

Figure 9. Initial water saturation in the reservoir.

\subsection{Development of the well model in OLGA}

For developing the well model in OLGA, one pipe with a length of $1612 \mathrm{~m}$, a diameter of $0.1397 \mathrm{~m}$ (5.5 inch), and roughness of $15 \mu \mathrm{m}$ is considered for representing the production tubing. Another pipe with the same length but a diameter of $0.2159 \mathrm{~m}$ (8.5 inch) is considered for representing the wellbore. It is assumed that oil is produced from 13 zones in the well and each zone contains two hypothetical sections. Therefore, the production tubing and wellbore are discretized to 26 hypothetical sections, each $62 \mathrm{~m}$ long. The simplified model for oil production from each zone is represented in Figure 10.

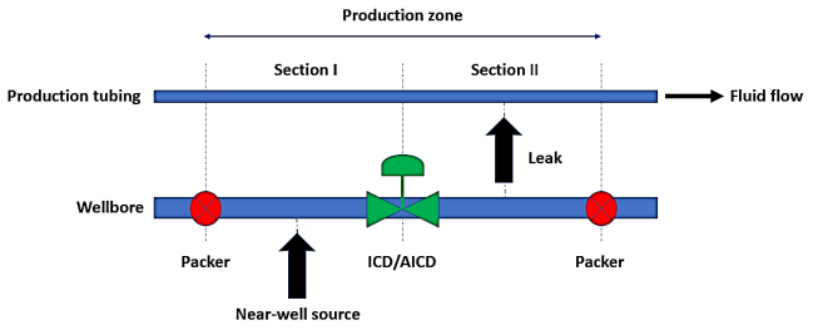

Figure 10. Simplified representation of a single production zone.

As can be seen in the figure, in order to stop flowing the reservoir fluids between different zones in the annulus, each production zone in the wellbore is separated by two packers. Moreover, by using a near-well source connected to the ROCX model, the reservoir fluids enter the wellbore after passing an inflow control device located in the first section of the wellbore. The reservoir fluids that pass through the inflow control device enter the production tubing via a leak connected to the second section of the production tubing and move towards the heel of the well. This setup has been proposed and used in (Aakre, 2017).

Based on the estimation of oil production from the well 16/2-D-12, and considering the frictional pressure drop in the well and pressure difference across the ICDs and AICDs, the pressure drawdown for this well is considered to be 12 bar. Moreover, the hole diameter of the equivalent valve is calculated as $d=0.0108 \mathrm{~m}$.

In order to implement the autonomous behavior of the AICD in OLGA, a controller must be used for chocking the AICD based on the characteristics of the AICD and reservoir fluid mixtures. For developing the model for oil production from the well 16/2-D-12 with RCP valve completion, the Table Control module in OLGA is used for controlling the valve. In this model, at first, by using the Transmitter module in OLGA, the water cut of the fluid mixture is measured. Then the Table Control, based on the measured water cut of the fluid mixture and some tabulated data (based on experimental data for the behavior of the RCP valve), provides a corresponding control signal for partially chocking the RCP valve.

\section{Results and discussion}

In this chapter, the obtained simulation results from the OLGA/ROCX model are presented and discussed. Besides, the functionality of ICD and RCP in improving oil recovery is evaluated. The simulations have been conducted for three cases: a) open-hole well, b) well with ICD completion, c) well with RCP completion.

\subsection{Fluid flow distribution and time of water breakthrough}

Figure 11 shows the oil saturation contours near the open-hole well right after the water breakthrough. The well consists of 13 zones and the 3D contour illustrates the oil saturation distribution from all the 13 zones.

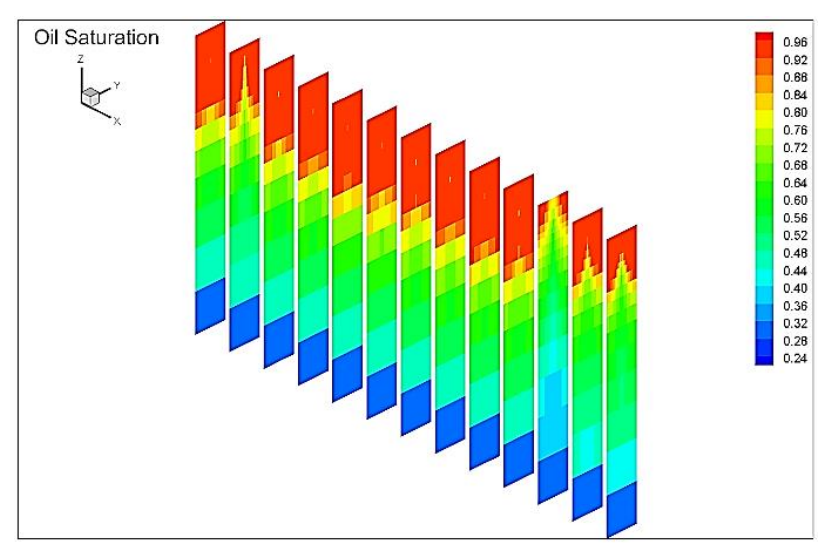

Figure 11. Oil saturation distribution right after the water breakthrough in the open-hole well. 
As shown in the contours, once the water breakthrough takes place, the water saturation profile has a conical shape. Besides, it can be clearly seen that the water cone grows faster and breaks into the well sooner at the heel compared to the toe of the well. It is obvious that the early water breakthrough occurs in the high permeable zones ( the $2^{\text {nd }}$ and $11^{\text {th }}$ zones) and the water cone develops much faster in these zones. Based on the obtained results, the water breakthrough for the openhole well takes place on the $3^{\text {rd }}$ day of production.

The oil saturation contours for the reservoir near the well 16/2-D-12 with considering inflow control devices right after the water breakthrough are illustrated in Figure 12. The well consists of 13 zones and the 3D contour illustrates the oil saturation distribution from all the 13 zones.

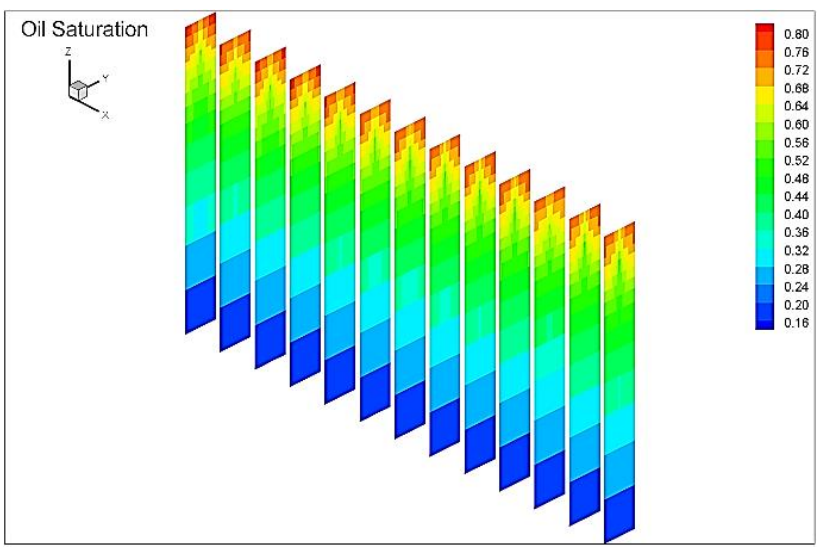

Figure 12. Oil saturation distribution right after the water breakthrough for the well with inflow control devices.

The simulation results show that the water breakthrough takes place on the $258^{\text {th }}$ day of production. As a result, by completion of the well 16/2-D-12 with ICD or RCP valves, the water breakthrough can be delayed by 255 days compared to the open-hole well. Moreover, By comparing Figure 11 and Figure 12, it can be concluded that the inflow along the well completed with inflow control devices is much more balanced compare to the open-hole well. Therefore, by using the inflow control devices the flow influx along a horizontal well can be effectively evened out.

\subsection{Accumulated oil and water production}

In order to investigate oil production and comparing the performances of different inflow control devices, accumulated oil and water are the two most important parameters that must be taken into account. Figure 13 illustrates the accumulated oil and water produced from the well $16 / 2-D-12$ by considering ICD and RCP completions. As can be seen in the figure, after 750 days of production, there is a very small difference between accumulated oil in the ICD and RCP cases. However, due to the choking effect of the RCP valve for low viscous fluids, the amount of accumulated water drops by $11.9 \%$ when the well is completed with RCP valves.
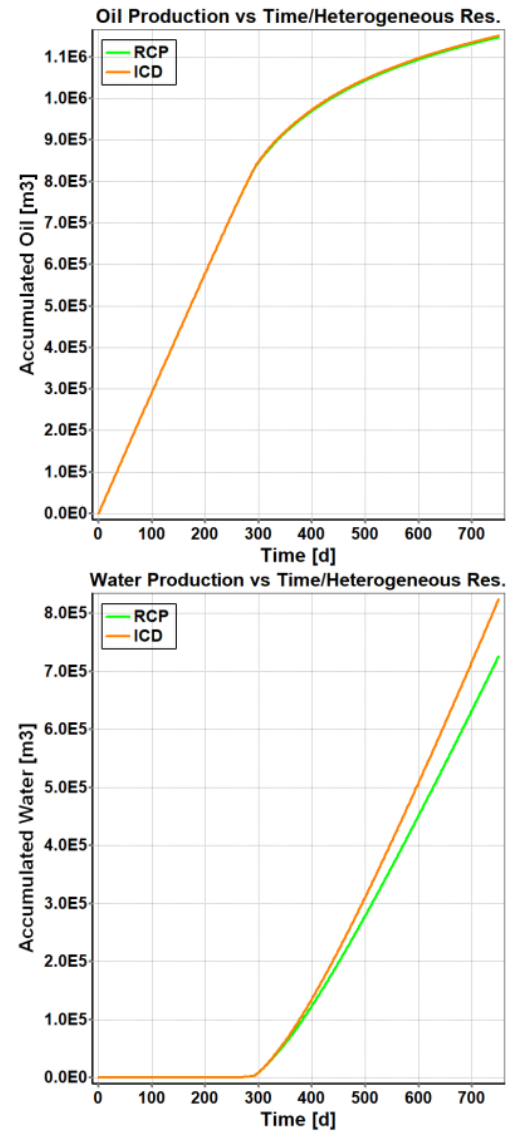

Figure 13. Accumulated oil and water from the well 16/2D-12 with ICD and RCP completions.

\subsection{Oil and water flow rate}

Figure 14 illustrates the volumetric flow rate of oil and water production from the well 16/2-D-12. As shown in the figure, just after starting the production, the oil flow rate in the RCP and ICD cases reaches its peak. By increasing the water saturation around the wellbore in the subsequent days, the rate of oil production experiences a slight decrease until the time of water breakthrough. At the time of water breakthrough, the water saturation near the wellbore exceeds the irreducible water saturation and as a result, water enters the well. Once water begins to enter the well, the reservoir tends to produce more water than oil. Consequently, after the water breakthrough, the rate of oil production drops substantially. The oil production can be continued until the oil saturation falls below the residual oil saturation. Therefore, after 750 days some amount of oil is produced. According to Figure 14, over the whole period of production (750 days), oil production in both the ICD and RCP cases is almost similar. As a result, it can be concluded that practically there is no difference between using ICD and RCP with respect to oil flow rate over the first 750 days of production. However, after water breakthrough, due to the capability of the RCP valve for choking the water back, the diagram of the water flow rate in the RCP case, falls below that of the ICD case. The simulation results 
show that the well completed by RCP valves reduces the rate of water production by $13.4 \%$ compared to using ICDs after 750 days of production.
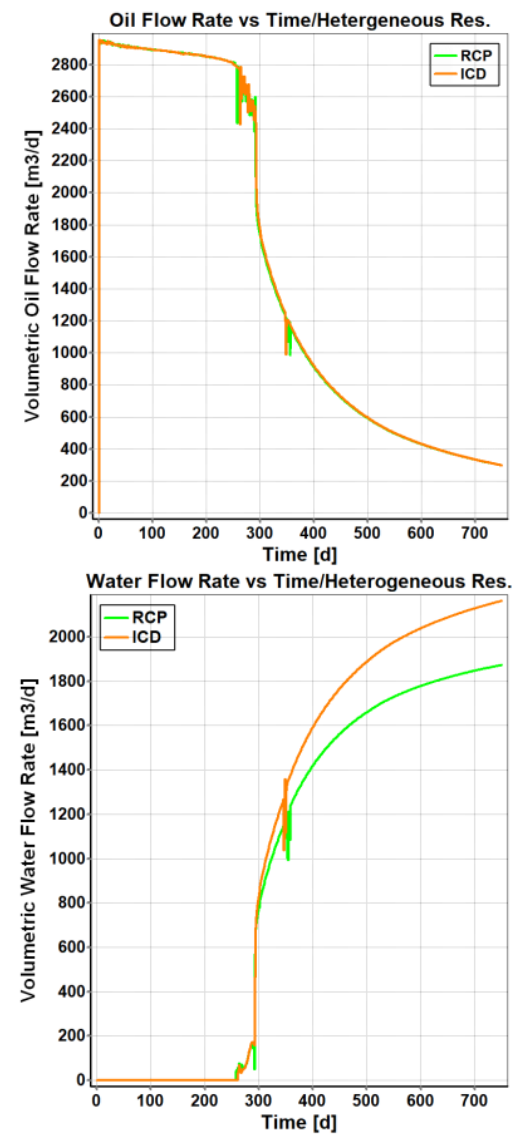

Figure 14. Flow rate of oil and water for the well 16/2D-12 with ICD and RCP completions.

\section{Conclusion}

The obtained results show that for both the open-hole well and the well with inflow control devices, water begins to enter the well from the heel side due to the heel-toe effect. Moreover, due to the faster development of the water cone in the high permeable zones, the early water breakthrough takes place sooner in these zones. Early water breakthrough leads to a significant drop in oil production, and this problem must be tackled to achieve cost-effective oil production. Both ICDs and RCPs can effectively even out the flow influx along the horizontal well and consequently delay the water breakthrough significantly. Since RCPs remain fully open before the time that water breakthrough occurs, there is no difference between the functionality of ICDs and RCP valves in delaying the time of water breakthrough. However, since the RCP valve opening is sensitive to the fluid viscosity, these valves have a capability for chocking the unwanted fluids. According to the simulation results, using RCP valves for the JSF condition can significantly reduce water production. By completion of the well 16/2-D-12 with RCP valves, the accumulated water production can be reduced by $11.9 \%$ during the first 750 days of production. Besides, using RCP valves can reduce the flow rate of water production by 13.4 after 750 days. Furthermore, by evaluating the simulation results it can be concluded that using RCP valves has a negligible impact on both the accumulated oil production and flow rate of oil production from this well compared to using ICDs. Therefore, by completion of the well 16/2-D-12 with RCP valves more costeffective oil production can be achieved.

\section{Referrences}

Haavard Aakre. The impact of autonomous inflow control valve on increased oil production and recovery. $\mathrm{PhD}$ thesis, University College of Southeast Norway, 2017.

Stian M. Askvik and Ivar L. J. Sørheim. Dynamic Autonomous Inflow Control Device-Performance prediction and experimental investigation of a specific rate controlled production valve design. Master's thesis, NTNU, 2017.

Omar J. Chammout, Bisweswar Ghosh and Mohamad Y. Alklih. Downhole flow controllers in mitigating challenges of long reach horizontal wells: A practical outlook with case studies. Journal of Petroleum and Gas Engineering: 97110, 2017.

Equinor. Crude oil assays. 2020. https://www.equinor.com/no/what-we-do/crude-oil-andcondensate-assays.html.

Wei Fang. Evaluation of low salinity injection EOR potential in Johan Sverdrup Field. Master's thesis, University of Stavanger, 2017.

Nanji Hadia, Havard H. Lehne, Kanwar G. Kumar, Kristoffer A. Selboe, Feb A. Stensen and Ole Torsater. Laboratory Investigation of Low Salinity Waterflooding on Reservoir Rock Samples from the Frøy Field. SPE Middle East Oil and Gas Show and Conference, Bahrain, 2011.

Martin Halvorsen, Martin Madsen, Mathias V. Mo, Ismail I. Mohd, and Annabel Green. Enhanced oil recovery on troll field by implementing autonomous inflow control device. SPE Bergen One Day Seminar, Norwey, 2016.

Philip C. Iheanacho, Djebbar Tiab and Alpheus O. Igbokoyi. Vertical-Horizontal permeability relationships for sandstone reservoirs. Nigeria annual international conference and exhibition, Nigeria, 2012.

Hans-Martin Kaspersen. Reservoir Characterization of Jurassic Sandstones of the Johan Sverdrup Field, North Sea. Master's thesis, University of Oslo, 2016.

Vidar Mathiesen, Bjernar Werswick, Haavard Aakre and Geir Elseth. Autonomous Valve, A Game Changer Of Inflow Control In Horizontal Wells. Offshore Europe Oil and Gas Conference and Exhibition, UK, 2011.

Norwegian Petroleum Directorate. Fact pages. 2020. https://factpages.npd.no/en/field/pageview/all/26376286.

Mathias Tangen. Wettability Variations within the North Sea Oil Field Frøy. Master's thesis, NTNU, 2012.

The Engineering Toolbox. Orifice, Nozzle and Venturi Flow Rate Meters. 2004. file:///C:/Users/alimo/OneDrive/Skrivebord/Orifice/Orifice $\% 20$ Nozzle\%20and\%20Venturi\%20Flow\%20Rate\%20M eters.html. 